\title{
A Review of Effective Waste Management from an EU, National, and Local Perspective and Its Influence: The Management of Biowaste and Anaerobic Digestion of Municipal Solid Waste
}

\author{
Mebrahtom Negash Araya \\ England, UK \\ Email:mnaraya1@sheffield.ac.uk,mebrahtoma@yahool.com
}

How to cite this paper: Araya, M.N. (2018) A Review of Effective Waste Management from an EU, National, and Local Perspective and Its Influence: The Management of Biowaste and Anaerobic Digestion of Municipal Solid Waste. Journal of Environmental Protection, 9, 652-670. https://doi.org/10.4236/jep.2018.96041

Received: April 3, 2018

Accepted: May 28, 2018

Published: May 31, 2018

Copyright $\odot 2018$ by author and Scientific Research Publishing Inc. This work is licensed under the Creative Commons Attribution International License (CC BY 4.0).

http://creativecommons.org/licenses/by/4.0/

\begin{abstract}
The waste management industry across the European Union (EU) has undergone radical change following the recognition that a move towards a sustainable society is essential for humankind. To this end, the EU has targeted household recycling targets of $50 \%$ by 2020 and $70 \%$ by 2030 in a bid to move towards a more sustainable and resource efficient society. Despite such targets and a number of relevant progresses in technology (such as incineration, composting, and anaerobic digestion), there are several challenges facing the municipal solid waste sector. The purpose of this review is to assess the EU, UK and local policies that are affecting the way waste is treated, Greater Manchester (GM) in the United Kingdom (UK), will be used as an example. The review focuses upon anaerobic digestion as a choice technology for waste management and assesses the influences of policies upon the application of anaerobic digestion at the EU and local level, finding that at current rates of recycling, local and national targets will be missed by approximately $7.3 \%$ in the year 2030, even in the best case scenario where the maximum amount of biowaste is managed under the current operational capacity. The review concludes that in order to improve the recycling bio-waste capacity on a local, national, and EU level, the introduction of the $\mathrm{AD}$ must be increased tremendously.
\end{abstract}

\section{Keywords}

Anaerobic Digestion, Waste, Recycling, Biogas, Resources Recover, Circular Economy 


\section{Introduction}

In recent years, the European Commission has shifted the waste paradigm towards the circumstance that gives value to waste as a commodity while stimulating improvements in resource productivity. Such paradigm change was triggered by central legislation from the European Union (EU), significantly influencing waste management policies and regulations in the EU Member States [1]. The EU directive on waste has become increasingly significant as the European Commission adopts an ambitious circular economy package, which includes revised legislative proposals on waste to stimulate the transition towards a less wasteful Europe [2]. The reviewed legislation on waste primarily looks beyond the waste reduction targets and instead considers a full economic cycle. This has established an ambitious and credible long-term path for waste management and recycling. That is safeguarded by an effective policy and targets such as: recycling municipal waste by $65 \%$, packaging waste by $75 \%$, and reducing landfill to most of $10 \%$ of municipal waste by 2030 , with tangible measures like a ban on landfilling of separately collected waste and promotion of economic instruments to discourage landfilling to sort the problems on the ground, to challenge the different situations across Member States, and ban the export of hazardous waste outside Europe [3]. This approach is anticipated to play a significant role in the quality of life of both EU citizens and the environment [2]. It is estimated that there will be growth up to $7 \%$ Gross domestic product (GDP) and $8 \%$ of annual turnover for business and around 170,000 direct job opportunities for citizens by 2035 [4]. For instance, in the United Kingdom (UK), this could have significant effects, such as potential creation of 50,000 new jobs and an additional $£ 3$ billion income of the GDP [5]. However, achieving these goals under existing circumstances is difficult without noteworthy investment in technology and/or changes in behaviour at the household level.

One substantial challenge for the waste management industry in Europe is the effective treatment of biowaste, which is the largest household waste stream in terms of mass. Biowaste is defined as a substance that is derived from living organisms and may be food, garden, or park waste [6]. Approximately $40 \%$ [7] of household waste is biowaste and around 52\% - 80\% (average 66\%) of this biowaste consists of water [8], amounting to around $100 \mathrm{~kg}$ of wastewater per household (2013) as an example, by mass, collected and managed by the UK waste management systems. On a local level, for example, in Greater Manchester (GM), this amounts to around 119,000 tonnes of water collected within the waste per annum (2013), which could be argued as an uneconomical method of waste management. This presents a significant challenge for the waste management industry if it is to improve management efficiency, consume less fuel and reduce greenhouse gas emissions in line with a circular economy.

The purpose of this review is a three-fold assessment of the current state of waste management across Europe, from an EU and local perspective in the UK, using Greater Manchester as an example. The review first looks at the policies on these three levels and second assesses the current waste management strategies 
for biowaste at the EU, and GM levels. The review then closely examines how legislation affects the implementation of anaerobic digestion on a mass scale. It also assesses the current state of biowaste management in the EU, and GM, and identifies a need for improvement of the current systems.

\section{Effective Waste Management Policy and Strategy}

Effective waste management refers to the waste management cycle and includes; monitoring, production, collection, transportation, processing and disposal or recycling [9], as shown Figure 1.

Through these steps, the waste outputs and the respective environmental impacts can be managed effectively and responsibly. However, as a result of legal, technical, and commercial contributions, managing waste effectively according to the Waste Hierarchy has become a complex process. The Hierarchy is usually considered waste prevention, if not possible product recycling, only then material reuse, processing with energy recovery, such as incineration and digestion, and ultimately landfilling after all these previous steps [11]. Herewith, the landfill is usually the cheapest option for waste disposal and the costlier processing provides an economic benchmark for recycling and reuse; prevention largely depends on product lifetime. The core component of effective waste management, therefore, is complex by nature and controversial in its context [12], as scholars have been debating the definition of waste for years [13]. Thus effective waste management as a concept depends upon attaining an informed consensus in collaboration with interested parties [14] such as waste management companies, environmental agencies, government, and social organizations. The dissimilarities in the definition and contextual interpretation of waste can understandably give rise to ownership and legal complications that can have a considerable impact on overall waste management processes. As a matter of simplicity, this section will be presented as three sub-sections discussing the effective waste management strategies employed by the EU, UK and GM. Generally, waste management and its historical development, the rules and directives that have governed it, and its future scenarios in the EU, UK and GM respectively, are discussed herein. Readers should also note that waste as defined by the EU based on directive 2008/98/EC-article 3 also enables various legal and societal interpretations of the term "waste" because it is defined in the following broad economic terms: "waste means any substance or object which the holder discards or intends or is required to discard" [15]. The definition implies that all

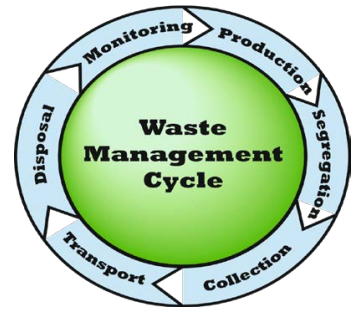

Figure 1. Waste management cycles [10]. 
depreciated goods can be considered as waste.

\subsection{European Union}

The Waste Hierarchy was derived from the fact that cheap landfilling and incineration were still the main methods by which Municipal Solid Waste (MSW) was disposed of, at the end of the 1980s [16]. By 1990, there were 186 MSW incinerators in the EU, declining by $52 \%$ in 2007 due to the availability of large regional landfills. However, obligations about incineration before landfilling triggered a decline in material recovery from waste (e.g. metals) [17]. Environmental impacts of landfilling were also relevant for that EU waste policy, for instance, emissions of greenhouse gasses as methane. In 1995, landfills in the EU accounted for around 3\% of total greenhouse gas emissions [18]. Such a high contribution was unacceptable; therefore, the management of waste required a change, with the aim of reducing greenhouse gas production through improved landfill diversion and consequently, it could be argued that the concern for gas emissions shaped waste management in the EU for the next twenty years. One of the key outcomes in the EU waste policy was the introduction of the landfill directive [19] equipped with strict requirements for landfills to prevent and reduce the adverse effects on the environment. This is also enhanced by the revised waste framework directive, which was established on the principle of minimizing disposal (reduce, reuse and recycle) and defined material recovery targets aiming to encourage recycling strategies.

The pretreatment of waste prior to landfill [20] but avoiding overcapacity of incineration and digesting, has been embedded in the EU directives, for instance the Landfill Directive, 1999 which limits the amount of biodegradable municipal waste going to landfills [19]. This favours expansion of waste management facilities, like $\mathrm{AD}$ technology, that have high priority according to the Waste Hierarchy. For the future, Europe 2020 strategy targets on climate change and energy [21] also prescribe prevention of greenhouse gasses [22]. All of these initiatives have paved ways for the EU policies aiming at material circulation in economies branded as a circular economy [23]. When it is broadly comprehended, this concept assumes less input of material resources and an increased share of renewable and recyclable materials, as well as reduced emissions, fewer material residuals and keeping the value of products in economies [24]. However, it will also be challenging to reduce the level of waste generation and align waste management objectives with those of the circular economy imultaneously. In practice, avoiding waste is the best waste management option; however, per capita municipal waste generation is still increasing in around one-third of all Member States. Moreover, two-thirds out of those waste prevention policies developed by the Member States focus on information and awareness raising, and most of these only emphasize change at the household level. Thus, for the EU expanding and strengthening of the existing policies are a key priority for reducing the environmental burden and reaching the overarching aims of a resource-efficient economy [25]. 


\subsection{United Kingdom}

In the last few years, the demand for waste treatment facilities in the UK has increased considerably, which is likely due to pressure from central government and the EU to divert biodegradable waste from landfill [26]. The country consequently presented an increase of $8.2 \%$ waste treatment capacity from 2012 to 2014 [26] as an example. Out of the 209 million tonnes of waste treated in 2014, the used facilities amounted to $0.9 \%$ energy recovery, $43.6 \%$ recycling and all recoveries other than energy recovery, $10.4 \%$ backfilling, 3.6\% incineration, $23.1 \%$ landfilling and $18.3 \%$ land treatment and release into water bodies.

The waste management regime has accordingly progressed from policies based on the control of waste disposal activities to embrace aims for waste prevention and recovery. This trend shapes growing attempts to harmonize waste policy objectives at both the EU and UK level [27]. The UK municipal waste definition has also been modified because some Local Authorities only report on waste collected from households as municipal waste, while others include commercial waste [28]. Likewise, the UK government included the biodegradable municipal waste (BMW) sent to landfill [28], which amounted to 7.7 million tonnes (2016), representing 22\% of the 1995 baseline value [26], as an example.

These factors encouraged waste management facilities to change and prompted the increment of facilities like $\mathrm{AD}$, which sets out five steps for dealing with waste in priority order according to article 4 of the revised EU Waste Framework Directive (Directive 2008/98/EC). For instance, from 2010 to 2015, the total electricity generated from Bioenergy saw a substantial $147 \%$ increase, out of which anaerobic digestion quantified 7.5\%; while as the electricity that generated from landfill decreased by $3.2 \%$ [21]. The decreased electricity generated from landfills is possibly a warning of reducing landfilled biowaste within those specified years and could suggest 0.2 million tonnes of residual household waste has moved away from the landfill. As mentioned earlier, this could acknowledge the implementation of the EU legislation on waste plus the recycling targets for municipal and packaging waste and for reducing landfill [21].

\subsection{Greater Manchester}

The waste management system in GM has a long history and it has been developed significantly in the past 10 years, particularly after the decision was taken by Greater Manchester Waste Disposal Authority (GMWDA) to work towards Zero Waste [29]. GMWDA is responsible for managing the waste of nine of the ten local authority districts in GM, with one (Wigan) being managed by Wigan Waste Disposal Authority (WWDA) [30]. In April 2009, the local authorities within GMWDA entered a 25-year Private Finance Initiative (PFI) contract with Viridor-Laing to manage GM's MSW, which accounts for $2.5 \%$ of the total waste in the UK. Likewise, Wigan has a 25-year contract with the FCC (UK) Limited waste management company to collect residual waste, Eco-ganix to collect mixed food and garden waste and Viridor to collect dry-recycling.

Both Waste Disposal Authorities (WDAs) are currently responsible for the 
MSW management in GM, agreeing to produce a Joint Waste Development Plan Document lasting until 2027 [31] with the tagline "Our aim is zero waste". As a result of the joint and coordinated activities the authorities diverted 54\% from landfill in 2013/14, an increase of approximately 13\% from the 2008/9 figures [16]. This was achieved through the infrastructure financed by the PFI contract, which built advanced in-vessel composting, Mechanical Biological Treatment (MBT), and Material Recovery Facility (MRF) facilities, as well as upgrading the existing household waste recycling centres to allow a more user-friendly approach to recycling.

Based on the Greater Manchester Joint Waste Development Plan Document (2012), it is evident that the Authority does not have any intention to add more waste treatment facilities (like energy recovery, recycling and composting) untill 2027 [31]. Rather, it favours waste prevention, the top priority according to the Waste Hierarchy. Thus, the focus is avoiding an increase in waste by the restricting household waste collection services, for example, by either moving to a three weekly system or reducing the capacity of residual waste through providing households with a smaller bin. Through these mechanisms and other behaviour change activities, the GMWDA developed a plan to reduce household waste to $400 \mathrm{~kg}$ per household by 2025 [32], of which biowaste will be around $160 \mathrm{~kg}$. Through those already existing waste facilities and listed prevention methods, the GMWDA aims to achieve the 2025 targets (e.g. 90\% diversion from landfill).

However, the worst case should also be considered. Moreover, its impact on environment and quality drop while it is transported to the transfer loading station and other related emissions should be here highlighted. Thus, in order to achieve the contract targets, GM must further increase its efforts towards $90 \%$ diversion from landfill to align with European and UK targets. Decentralizing industrial processes may potentially be a route towards achieving this. As stated before, they can reduce the cost of waste mobility and pollution, mainly by removing the water content of the biowaste at its source level, simultaneously enhancing society's awareness. This type of system demands a high social commitment, and thus generates links between people sharing the same purposes [33]. Ultimately, the concept that fundamentally believes waste is a resource, is not sustainable in the long term unless the producer (household) directly starts to benefit from it.

Figure 2 depicts that, there are currently 44 facilities across 23 sites, managing over 1.1 million tonnes of waste per year [34]. These are: the Educational Centres, which enhance the knowledge of the people towards recycling, Household Waste Recycling Centres, which are used to recycle and dispose of the household wastes safely, Mechanical Biological Treatment (MBT), which separates waste into several fractions such as light/heavy fractions, ferrous and non-ferrous metals, and organic materials; the In-Vessel Composting plant, which attaches the natural composting process, to recycle organic waste into quality compost products and for later use as a soil improver; the Thermal Recovery Facility, a 


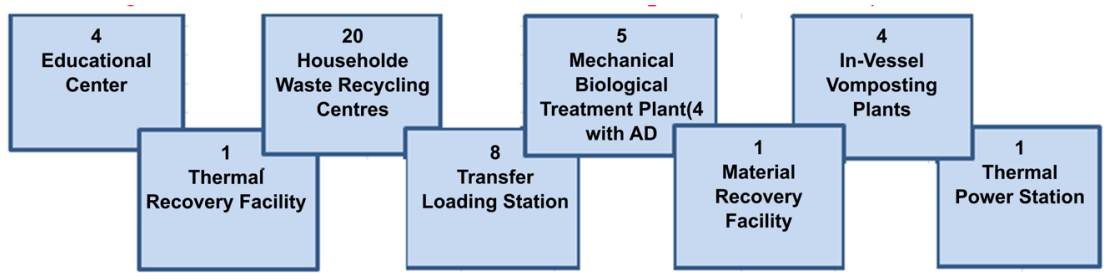

Figure 2. Summary of the waste processing facilities within GM [34].

process by which energy is produced from burning waste at high temperatures; Transfer Loading Stations, which are used as a place for the local waste collection vehicles to deposit their waste cargo prior to loading into larger vehicles; Material Recovery Facilities sort commingled recycling like glass bottles and jars; finally a Thermal Power Station is a combined cycle gas turbine power station within Greater Manchester. The quantity in each box of Figure 2 shows the total number of each facility in GM.

\subsection{Decentralized Waste Management Systems}

There is an argument to say that in order for local collection authorities to contribute to landfill diversion further, a decentralized system of waste management is preferable. The decentralized treatment is supposed to improve local economies, create jobs, use local resources, deliver quality products, and create less hazardous waste as a product of the process [35]. It also carries other indirect advantages such as reduced fuel consumption, reduced contamination of groundwater, reduced air pollution and lower road maintenance cost [36]. Generally speaking, a decentralized waste management system is usually assumed to have more benefits for the environment than otherwise, and may not produce the unwanted waste as a result of complex industrial processes, thus enabling further landfill avoidance.

The main impediment to the decentralized system is a higher cost per waste unit. Another problem with decentralized systems is that MSW is viewed as a great burden to the local environment and ecosystem (smells, rodents, hygiene) and creates a challenge compared to the existing waste management paradigm that allows people to forget about their waste once it is collected by the local authority. Yet a change in this behavior could allow communities to manage their waste and eliminate fuel expenditure for collection rounds. This is especially pertinent for biowaste as it is dense compared to packaging waste and carries an extra fuel burden as a result of its water content. This proposed paradigm makes the participation of the community especially crucial because decentralized management as a principle devolves authority to the citizens, who in turn become more responsible for their own waste management system. This is a specific responsibility requiring an assignment of subordinates with the necessary skills to manage both the waste flows and the $\mathrm{AD}$ process itself. The type of biowaste treatment that is mostly used in western countries is a centralized waste management system where methods such as the industrial AD or composting 
are implemented to manage food and/or garden waste. The difference between the two types of treatment is summarized in Table 1.

\section{Biowaste}

Biowaste is one the main environmental threats due to the production of methane from decomposed landfills. Thus, the EU developed a Landfill Directive (1999/31/EC) [38] that forced the Member States to reduce their biodegradable municipal waste (including biowaste). However, as it was mentioned in the previous sections, this directive didn't prescribe a specific waste treatment facility option by the Member States to be applied. Therefore, they have practiced the cheapest and easiest treatment methods such as incineration, which truly disregards the environmental benefits and cost, rather than using high resource efficiency and environmentally friendly treatment methods like the AD. However, with the application of the Waste Hierarchy and Waste Frame Directives (e.g. recycling targets) to the management of biowaste, waste treatment facilities like the $\mathrm{AD}$ have been given priority [18]. There has also been more emphasis on the $\mathrm{AD}$ treatment method of biowaste has also given with ratification of the four legislative proposals of the waste packages in 2017. Based on this waste package's target, at the end of 2023, the biowaste should be either collected separately or recycled at the source level (e.g. by home composting) [39]. Because biowaste, as a waste stream, has been given more focus by the EU, it is currently present a significant challenge for the economy and the environment and also because it is linked to binding targets in EU legislation and to deliverables of the Action plan for the circular economy [40]. For instance, biowaste is a source of nutrients, such as phosphate and nitrate. According to some sources, if the listed waste in the EU were treated effectively, it could improve the condition of $3 \%-7 \%$ of EU's depleted soil and deliver $€ 1.5$ - 7 billion [41].

Biowaste is characterized by a high organic matter and normally has a high-water content that accounts for around $52 \%-80 \%$ of the total mass of the waste. Biowaste can be thought of as waste from living organisms that is disposed of at a household level, for example meat, fish, vegetables, egg shells, coffee beans, or tea bags. This excludes refuse such as sewage sludge, manure, or

Table 1. The main differences between decentralized and centralized waste treat-ment [37].

\begin{tabular}{|c|c|}
\hline Centralized & Decentralized \\
\hline Transportation costs relatively high & Transportation costs relatively low \\
\hline $\begin{array}{c}\text { Economies of scale-non-adaptable to waste } \\
\text { reduction }\end{array}$ & $\begin{array}{l}\text { The local matter is a local resource adaptable } \\
\text { to the reduction }\end{array}$ \\
\hline Low-quality compost & High-quality compost \\
\hline Need advanced technology & Simple technology needed \\
\hline Large facilities & Small facilities \\
\hline High treatment cost & Low treatment cost \\
\hline
\end{tabular}


agricultural wastes [18] according to the European Commission. Biowaste is potentially problematic because it degrades to form gases such as methane, creates odours, attracts pests, and is relatively dense. The odours are particularly noticeable near waste management sites, notably composting plants, and at landfill sites where much biodegradable waste still ends up, creating public health and biodiversity issues. The density of biowaste is a product of the high-water content, which directly contributes to the high transportation cost and emission of carbon dioxide that is experienced in waste collection processes [6].

The economic problem for the industry is the high cost of transport because much water content is carried in biowaste. Thus, the hosting of decentralized $\mathrm{AD}$ systems for the treatment of biowaste on a local level may be an attractive avenue for future effective waste management by obviating the need for transportation of biowaste. Thus, decentralized processing could be attractive because it requires less transport.

\subsection{Biowaste in the UK}

Current waste infrastructure in the UK is partially designed to cope with the level of biowaste created in the UK, which stands at about 4 million tones [42] according to the UK Digest of Waste and Resource Statistics if one assumes that biowaste is the only food waste. This figure could double if garden waste is also considered. Even though composting and $\mathrm{AD}$ are commonly employed waste treatment facilities within the UK at the moment, a considerable amount of the biodegradable waste still is sent to landfill. Even not yet least due to the current landfill tax levy that is incurred on every tonne of waste sent to landfill. For example, in 2015, around 8 million tonnes of biodegradable waste, including biowaste, was landfilled [43]. Hence, the untreated biodegradable waste may pose a challenge to the UK waste industry if it isn't effectively managed, and more interestingly, in each year, insinuating waste is increasing correspondingly. Therefore, the challenge will be trickier unless comparable measures are taken. The action that has been taken by Wales, where funding is offered for free back garden Composters as a method of decentralized waste management [44], is exemplary for the rest of the UK since similar efforts may be required elsewhere if they are to have any noticeable effects on the overall waste and recycling targets.

\subsection{Biowaste in Greater Manchester}

Biowaste, as mentioned in section 2.2, has fallen at household level through the 'Love Food Hate Waste' campaigns launched in recent years within Greater Manchester. However, biowaste is still a significant proportion of the household waste bin [45]. As GMWDA figures indicate, $40 \%$ of waste collected at the kerbside is biowaste, but individual breakdowns of this biowaste waste are currently unobtainable. Nevertheless, the figures do indicate that GM produces more biowaste, than the national average. Based on figures from DEFRA (2017) the waste production per household was $407 \mathrm{~kg}$ in the year 2015 [42]. Since an average of 
biowaste at household level is around $40 \%$ of the mass production, thus, approximately $163 \mathrm{~kg}$ of biowaste is collected per person. Moreover, it is expected that there are around 2.3 people per household [46], thus, roughly $375 \mathrm{~kg}$ is collected from an average household. It is estimated that $1000 \mathrm{~kg}$ of residual household waste produces $992 \mathrm{kWh}$ [30] in energy from its biowaste; therefore, each household in GM could generate approximately $1 \mathrm{kWh}$ per day or 3000 MWh per year in GMWDA.

The current waste management systems in GM have looked at addressing this issue, and based on Figure 3, MSW has declined by approximately $9.4 \%$ over six years (2005/6 to 2010/11). Furthermore, the waste infrastructure in GM is such that any biowaste that enters the residual waste stream is separated at an MBT plant and utilized in an AD process. This could be argued as an extremely effective way to manage a large amount of waste, but it does have the drawback of the requirement for transportation and the need for highly skilled personnel to manage the technology properly.

\section{Anaerobic Digestion}

The previous sections of this review have covered waste policy from different perspectives and the treatment of biowastes at the EU, UK and GM levels. This section follows on from this by focusing on an $\mathrm{AD}$ system as a waste processing technology and examines how policy drivers detailed previously have allowed $\mathrm{AD}$ to be a successful technology within waste management today. The section will start with a background on $\mathrm{AD}$ and proceed to discuss industrial implementation with reference to policy drivers throughout. Anaerobic digestion is defined as the process by which microorganisms break down organic compounds into simpler compounds in the absence of oxygen, producing a gas composed primarily of methane and carbon dioxide [48]. The general principle is shown schematically in Figure 4. The AD reduces material volumes by about $60 \%$ during biogas production [49] while creating a fertilizer for soil replenishment at the same time. The process can last anywhere from a few days to around eight weeks, depending upon factors such as temperature, $\mathrm{pH}$, water/solids ratio, carbon/nitrogen ratio, mixing of the digesting material, the particle size of the

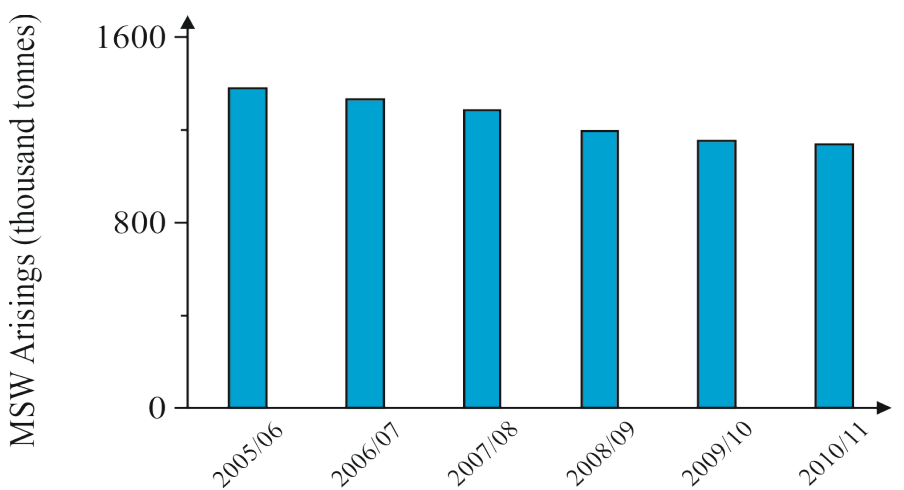

Figure 3. The municipal waste in Greater Manchester 2005/6 to 2010/11 [47]. 


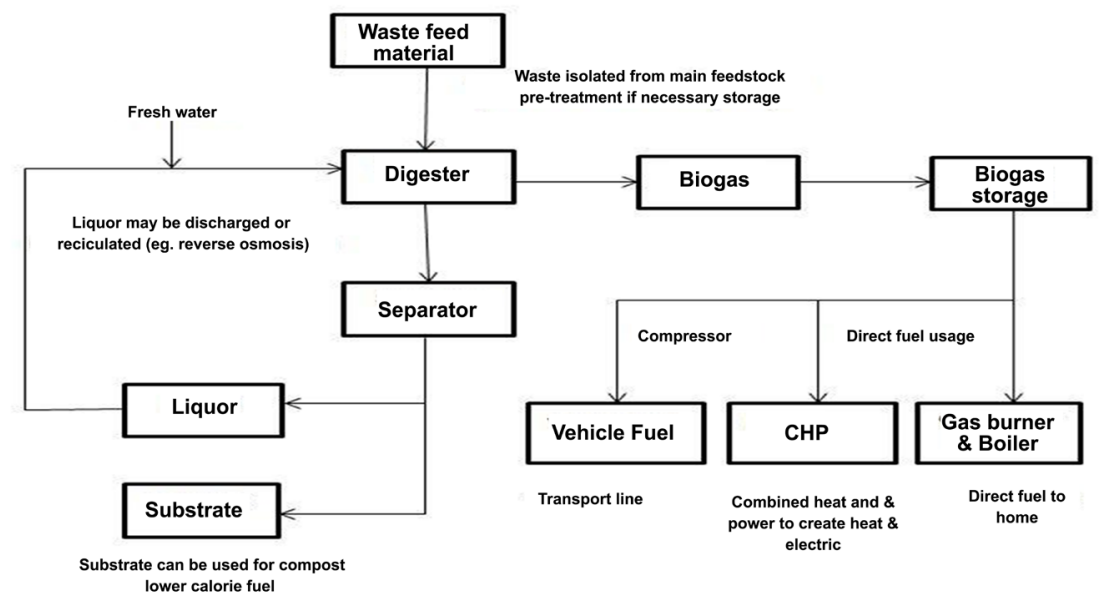

Figure 4. The Generic anaerobic flow chart [50].

material being digested, and retention time [48]. It also requires a careful balance of several factors, including organic load, salinity, and alkalinity, appropriate levels of which can be difficult to achieve and hard to control. In general, the $\mathrm{AD}$ feedstock mainly has four categories, Waste Water Treatment Plant (WWTP) sludge, biowaste, agricultural and industry.

Anaerobic Digestion (AD) is a process that has been understood for hundreds of years, probably since Alessandro Volta discovered that methane was produced from swamps [51]. However, it wasn't until 1859 that the process was understood well enough to be used as an industrial technology. The first reported digestion plant was built in Bombay to process sewage in 1859 [48] [52]. This would have been considered a novel waste management strategy that could bring some significant benefits such as reduced organic matter volumes. However, as this was primitive in its nature, it wasn't until nearly 40 years later that further plants were built. The UK was one of the next reported nations to utilize AD; however, it took the idea of $\mathrm{AD}$ one step further by recuperating the biowaste from a sewage treatment facility and subsequently using them to fuel street lamps [52]. This was the first example of a gas that was produced in a septic tank designed for small amounts of human waste. After anaerobic bacteria were investigated in the 1930s by the research led by Buswell [53] and others, companies found ways to improve the effectiveness of gas recuperation, for example by preventing methane hydrate formation and conversion into methanol or monoethylene glycol [48]. This played a significant role in the development of AD technology [51].

Present day AD systems are influenced by factors such as local environmental regulations (EU Directive 2009/28/EC) and other policies governing land use and waste disposals, such as agriculture and renewable energy regulatory frameworks, policies to reduce GHG emissions, incentives that have ensured the success and viability of the $\mathrm{AD}$, and mandatory requirements to divert the organic waste from landfills [54]. One typical example of this was in 2008 when the UK introduced the Renewable Transport Fuels Obligation (RTFO), designed to 
obligate fuel suppliers to source $5 \%$ of their transport fuels from renewable sources by 2014. This was significant in widening the construction of AD plants further in the UK [55].

Anaerobic digestion carries significant advantages over other renewable energy technologies (wind, tidal and solar) such as the potential for generation of constant energy supply and storage ability in the national grid [56]. However, $\mathrm{AD}$ operators still face a number of challenges, one of which is access to regular, consistent, and appropriate waste feedstock over the life of the AD plant, some of which are built for periods exceeding 25 years. MSW by its nature is inconsistent; therefore, it can be very challenging to create AD plants that can successfully manage MSW on a large scale. Nevertheless, construction of AD facilities has increased across Europe and is a leading waste management technology [57].

The process of $\mathrm{AD}$ creates biogas, which itself creates issues that must be accounted for in planning. In many cases, the authorities become more concerned with the potential environmental impacts of $\mathrm{AD}$ systems (pollution, reduction, waste treatment, greenhouse gas emission control), unlike other renewable energy technologies where energy output is normally of utmost consideration [51]. This may be a reason why AD plants have only recently been introduced on a wider scale in different parts of the world. However, such systems are normally decentralized and require less management than centralized systems. AD systems in the developed world are predominantly centralized systems with complicated processes, which are relatively few in number and of a large scale.

\subsection{AD in the EU}

In addition to the previously mentioned drivers of $\mathrm{AD}$ development, the price of electricity generated from the combustion of biogas in a CHP engine has also played its own role in spreading the construction of $\mathrm{AD}$ plants across EU countries, which also has a direct relationship with the number of $\mathrm{AD}$ plants that are constructed in the Member States [58]. Hence, the nations that are more likely to implement $\mathrm{AD}$ are the ones that offer the greatest financial incentives for electricity generation. However, as mentioned in 2.1 , the recently revised waste framework directive, as an example, also has its own input on expanding and maximizing the number of the $\mathrm{AD}$ systems across the member countries and attracting investors in the waste industry [23].

MSW production per person in the EU was $481 \mathrm{~kg}$ in 2013 [59] and there was also a trend of reduction by $0.8 \%$ from 2002-13 [59]. Therefore, a fair estimation of the EU's MSW is $473 \mathrm{~kg}$ per person per year, of which $189 \mathrm{~kg}$ is potentially biowaste based upon previously mentioned figures. The population of the EU was estimated to be approximately 510 million in 2015 [60], therefore, approximately 96 million tonnes of biowaste were produced in 2015. Thus, the AD plants that were built prior to 2015 could only process $9.4 \%$ of the total potential arising from biowaste. In addition, around $40 \%$ figure is an average value for biowasteas a percentage of the total MSW, but in reality, the value of biowaste can fluctuate from $18 \%$ to $60 \%$ [7] depending upon the local conditions. Based 
upon such estimations, the EU may have to manage up to 142 million tonnes of biowaste per year. This shows that there is a possibility that the facilities could, in theory, have $93.8 \%$ less capacity than required for the worst-case scenario, indicating a requirement for significant investment in infrastructure if the EU wishes to achieve its targets through further implementation of $\mathrm{AD}$.

\subsection{AD in the UK}

In 2010, the UK government made the decision to work towards a "Zero Waste" economy and to initiate measures to enhance energy from waste by encouraging people to recycle more of the waste arising from the household [61]. This change was to be led by businesses, which were given the opportunity to initiate the change through renewable energy technologies such as $\mathrm{AD}$. As a result, the Government's Structural Reform Plans (2010) included actions to endorse increased energy from waste through $\mathrm{AD}$, and the installation of the $\mathrm{AD}$ facilities has resultantly seen a marked increase in recent years, alongside the overall $\mathrm{AD}$ capacity. From 2013 to 2015 there was a 57\% increase in the number of AD systems and a $62 \%$ increase in total capacity [58].

In 2014, there were $161 \mathrm{AD}$ plants in the UK that are outside the water industry and small agricultural plants, with the capacity to produce $143 \mathrm{MW}$ of electrical power, demonstrating an increase of $34 \% \mathrm{MW}$ capacity from the previous year. It was also identified an estimated $30 \mathrm{MWe}$ of additional capacity would be constructed in 2015 [58]. However, in January 2015, there were only 161 functional AD plants, capable of processing around 628 tonnes of biowaste in an hour, or 5.5 million tonnes per year. Using population and waste arisings statistics from 2014, and accountable for improvements in recycling performance and waste arisings, the waste produced at the household level [12] was approximately $415 \mathrm{~kg}$ per person in 2015. Since the population of the UK was approximately 65 million in 2015 [62], it is estimated that approximately 10.7 million tonnes of biowaste were produced in 2015. This estimation indicates that the AD capacity in the UK could only cover $51 \%$ of the required capacity for the biowaste arising in 2015, inferring that further capacity is required to achieve an effective waste management strategy for the entirety of the UK's biowaste. Furthermore, there is a problem in that centralized systems are already in place in many areas, which require the householder to behave in a specific way in order to achieve biowaste recycling. It may be necessary to emphasize rural regions that are not served by centralizing $\mathrm{AD}$ systems to improve biowaste recycling in the future.

\subsection{AD in Greater Manchester}

In Greater Manchester, there are four Mechanical Biological Treatment (MBT) facilities using $\mathrm{AD}$ with a total capacity of 440,000 tpa. As mentioned previously, the average mass of biowaste per household is $380 \mathrm{~kg}$ in a year and there are approximately 1,128,000 (2013) households in GM. Based on this data, there is a possibility of the production of 430,000 tpa of biowaste. Therefore, it can be 
concluded that the current facilities have the potential to recycle all the biowaste that would be produced by GM. However, these facilities also treat all the biodegradable waste produced within GM [34]. When the content of biowaste at the household level reaches $60 \%$, the total mass would be $574 \mathrm{~kg}$ (2013) of biowaste at the household level and this indicates a potential total of 650,000 tonnes of biowaste in GM. This shows that the local facilities could, in theory, have $47 \%$ less capacity than required for the worst-case scenario. Even in the best-case scenario, it will be extremely difficult to achieve the 2030 recycling target outlined by the government (70\%). Although the waste generated by persons in GM is decreasing and the amount of recycling of household waste is increasing (Figure 5), the population size has increased by an average of $0.56 \%$ annually since 2001 [63].

Therefore, taking the average rates, and other variables for the coming years constant, the recycling rates will be approximately $54.7 \%$ and $62.7 \%$ in the years 2020 and 2030, respectively. Thus, without further changes, GM will miss its 2030 waste and recycling target by $7.3 \%$. This could be a damning scenario for GMWDA and VL, which is a waste company in Manchester which is jointly owned by John Laing and Viridor, waste. Therefore, new avenues for recycling must be explored, including the possibility of decentralized $\mathrm{AD}$ facilities that can be voluntarily managed by community groups and/or leaders. This can enhance society involvement in the whole waste process.

\section{Outlook and Summary}

Effective waste management strategies are a fundamental requirement for the world to move towards a truly waste-free society. The EU has acknowledged this fact through the implementation of several regulations within the Waste Framework Directive to stimulate improved recycling rates and landfill diversion within its Member States. The achievement is more plausible as making waste a resource and looking beyond the reduction targets towards a full economic cycle is materialized through the circular economy. The intention is to create job opportunities and GDP growth within the Member States.

However, both reducing the level of waste generation and aligning waste

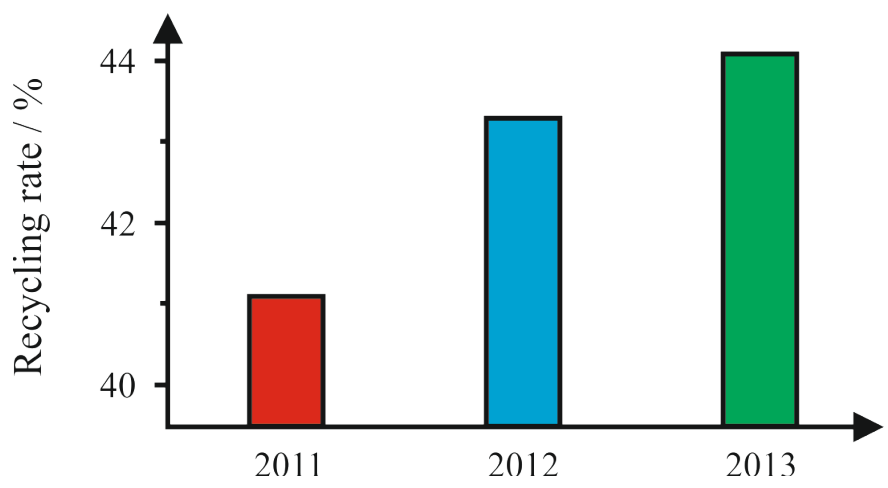

Figure 5. Recycling rates from household waste in England [64]. 
management objectives with those of the circular economy are challenging. Parallel, the existing waste prevention policies needs to be expanded and strengthened among and within the Member State. For instance, after the modification of its waste definition and indicators (2010) to align with both the EU Waste Hierarchy and Waste Framework Directive, the UK obtained a rise of $8.2 \%$ in waste treatment capacity by reducing $0.7 \%$ of landfilling (2012 to 2014). However, in 2014, the landfill was still the second most used final waste treatment. The alignment of the UK towards the EU waste regulations and the directive is also reflected in local MSW contracts (for instance GM), by building high-tech technologies like MBT, In-Vessel Composting plant and Thermal Recovery Facilities to improve recycling and landfill diversion. However, GM could fall short of the 2030 target of $70 \%$ recycling by 7.3 , taking the average rates and other variables for the coming years as constant. Thus, maximizing the current AD capacity and investing further in the $\mathrm{AD}$, as a decentralized form, may be valuable for GM to achieve recycling and landfill targets. However, factors such as contract obligations from Viridor Laing, FCC, UPM and Eco-ganix, availability of space for locating facilities in a densely populated area, space availability, odour, and seasonality of waste make decentralization of $\mathrm{AD}$ unattractive.

\section{Acknowledgements}

The author wishes to acknowledge the University of Manchester Metropolitan (MMU), Waste Research Department for supporting this study by providing in-kind support (office and other related utilities).

\section{References}

[1] European Commission (2016) European Action for Sustainability. Eur-lex.europa.eu., Strasbourg.

[2] European Commission (2015) Closing the Loop: An EU Action Plan for the Circular Economy. EC, Brussels, 2015. CO, 614.

[3] European Commission (2015) Closing the Loop: Commission Adopts Ambitious New Circular Economy Package to Boost Competitiveness, Create Jobs and Generate Sustainable Growth. EC. [Online] europa.eu, 122. http://europa.eu/rapid/press-release_IP-15-6203_en.htm. 15-6203

[4] Pierre, H. Circular Economy Package: What's in It.

[5] ESA (2013) Going for Growth: A Practical Rout to a Circular Economy. esauk.org, London.

[6] Eur-Lex (2008) On the Management of Bio-Waste in the European Union. s.l.: eur-lex.europa.eu, 52008DC0811.

[7] Eur-Lex (2018) Municipal Waste Statistics. eur-lex. [Online] ec.europa.eu, 01. http://ec.europa.eu/eurostat/statistics-explained/index.php/Municipal_waste_statist ics

[8] Fricke, K., et al. (2007) Operating Problems in Anaerobic Digestion Plants Resulting from Nitrogen in MSW. Waste Management, 27, 30-43. https://doi.org/10.1016/j.wasman.2006.03.003

[9] Demirbas, A. (2011) Waste Management, Waste Resource Facilities and Waste 
Conversion Processes. Energy Conversion and Management, 52, 1280-1287. https://doi.org/10.1016/j.enconman.2010.09.025

[10] Anon Figure Legend Waste Management Collection, Production, Segregatio, Collection, Transportation, Disposal an Dmonitoring. Googlesearch. [Online] nd. https://www.google.co.uk/search?rlz=1C1CHBD_en-GBGB788GB788\&tbm=isch\&s $\underline{\mathrm{a}=1 \& \text { ei=OO_PWufQMIeUgQa51beADQ\&q=figure\%2Blegend\%2Bwaste\%2Bmana }}$ gement $\% 2 \mathrm{Bcollection} \% 2 \mathrm{Cproduction} \% 2 \mathrm{C} \% 2 \mathrm{Bsegregatio} \% 2 \mathrm{C} \% 2 \mathrm{Bcollection} \% 2 \mathrm{C} \% 2 \mathrm{Bt}$ ransportation $\% 2 \mathrm{C} \% 2 \mathrm{Bdisposal} \% 2 \mathrm{Ban} \% 2 \mathrm{Bdmonitoring \& oq}=\mathrm{fi}$

[11] Read, A.D. (1999) Making Waste Work: Making UK National Solid Waste Strategy Work at the Local Scale. Resources, Conservation \& Recycling, 26, 259-283. https://doi.org/10.1016/S0921-3449(99)00015-4

[12] DEFRA (2011) Guidance on Applying the Waste Hierarchy. Gov.uk, London, 13530.

[13] White, P.R., Franke, M. and Hindle, P. (1995) Integrated Solid Waste Management a Life Cycle Inventory. Glasgow: Blackie Academic and Professional, 43, 1-3.

[14] Thabrew, L., Wiek, A. and Ries, R. (2008) Environmental Decision Making in Multi-Stakeholder Contexts: Applicability of Life Cycle Thinking in Development Planning and Implementation. Journal of Cleaner Production, 17, 67-76. https://doi.org/10.1016/j.jclepro.2008.03.008

[15] Eur-Lux (2008) DIRECTIVE 2008/98/EC of the European Parliamment and of the Council. s.l.: eur-lex.europa.eu, 32008L0098.

[16] DEFRA (2013) Incineration of Municipal Solid Waste. Gov.uk, London, PB13889.

[17] Powell, J.C. (1996) The Evaluation of Waste Management Options. Waste Management \& Research, 14, 515-526. https://doi.org/10.1177/0734242X9601400601

[18] European Commission (2016) Biodegradable Waste. European Commission Environment. http://ec.europa.eu/environment/waste/compost/

[19] European Commission (2018) Waste. European Commission.

[20] Komilis, D.P., Ham, R.K. and Stegmann, R. (1999) The Effect of Municipal Solid Waste Pretreatment on Landfill Behavior: A Literature Review. Waste Management \& Research, 17, 10-19.

[21] Eurostat (2017) Europe 2020 Indicators-Climate Change and Energy. http://ec.europa.eu/eurostat/statistics-explained/index.php/Europe_2020_indicators -_climate_change_and_energy

[22] Edwards, J., Othman, M. and Burn, S.A. (2015) Review of Policy Drivers and Barriers for the Use of Anaerobic Digestion in Europe, the United States and Australia. Renewable and Sustainable Energy Reviews, 25, 815-828. https://doi.org/10.1016/j.rser.2015.07.112

[23] Gregson, N., et al. (2015) Interrogating the Circular Economy: The Moral Economy of Resource Recovery in the EU. Economy and Society, 44, 218-243. https://doi.org/10.1080/03085147.2015.1013353

[24] EEA (2016) Circular Economy in Europe. EEA, Luxembourg.

[25] Oakdene, H., Peter, L., Edward, S., Olivia, B., Harry, S. and Nia, B.L. (2017) Towards a Circular Economy-Waste Management in EU. STOA, PE 581.913.

[26] DEFRA (2018) UK Statistics on Waste. Gov.uk, London.

[27] Lazarevic, D., Buclet, N. and Brandt, N. (2010) The Influence of the Waste Hierarchy in Shaping European Waste Management: The Case. Regional Development 
Dialogue, 31, 124-148.

[28] EEA (2013) Municipal Waste Management in the UK. Copenhagen Resource Institute, Copenhagen.

[29] DEFRA (2015) Digest of Waste and Resource Statistics-2015 Edition. Gov.uk, London, PB14292.

[30] Environment FCC (2014) FCC Environment Is on the Road to Wigan's Residual Waste Contract.

http://www.fccenvironment.co.uk/fcc-environment-is-on-the-road-to-wigans-resid ual-waste-contract.html

[31] GMWA (2012) Greater Manchester Joint Waste Development Plan Document. GMAU, Manchester.

[32] GMWDA (2016) Resource Greater Manchester. GMWDA, Manchester.

[33] Raufflet, E. (2008) Re-Mapping Corporate Environmental Management Paradigms. International Studies of Management and Organization, 36, 54-72. https://doi.org/10.2753/IMO0020-8825360203

[34] GMWDA (2018) Our Aim Is Zero Waste. https://www.gmwda.gov.uk/

[35] Singh, N. (2016) Solid Waste Management-A Look at Some Technologies of Department of Atomic Energy. Environment and Urbanization Asia, 7, 149-152. https://doi.org/10.1177/0975425316629833

[36] Tchobanoglous, G., Burton, F.L. and Stensel, H.D. (2010) Wastewater Engineering: Treatment, Disposal, Reuse. Fourth Edition, Metcalf \& Eddy, Inc., New York, 1-12.

[37] Wilderer, P. and Schreff, D. (2000) Decentralized and Centralized Wastewater Management a Challenge for Technology Developers. Water Science \& Technology, 41, 1-8.

[38] Eur-Lex (1999) Council Directive 1999/31/EC.

[39] European Commission (2018) EU Ambassadors Approve New Rules on Waste Management and Recycling.

http://www.consilium.europa.eu/en/press/press-releases/2018/02/23/eu-ambassador s-approve-new-rules-on-waste-management-and-recycling/

[40] Eur-Lex (2018) Measuring Progress towards Circular Economy in the European Union-Key Indicators for a Monitoring Framework. Eur-lex.europa.eu, Strasbourg, 52018SC0017.

[41] Eur-Lux (2010) On Future Steps in Bio-Waste Management in the European Union.

[42] DEFRA (2017) Digest of Waste and Resource Statistics-2017 Edition. Gov.uk, London, PB14454.

[43] DEFRA (2016) UK Statistics on Waste.

[44] Chartered Institution of Wastes Management (CIWM) (2018) Composting. https://www.ciwm.co.uk/ciwm/knowledge/composting.aspx

[45] GMWDA (2012) Waste Management Strategy.

[46] New Economy (2016) Greater Manchester Key Facts.

[47] DEFRA (2010) Annual Report 2010/11.

[48] Traversi, D., et al. (2015) Microbial-Chemical Indicator for Anaerobic Digester Performance Assessment in Full-Scale Wastewater Treatment Plants for Biogas Production. Bioresource Technology, 186, 179-191.

https://doi.org/10.1016/j.biortech.2015.03.042

[49] Carrère, H., et al. (2010) Pretreatment Methods to Improve Sludge Anaerobic De- 
gradability: A Review. Journal of Hazardous Materials, 183, 1-15.

[50] Holm-Nielsen, J.B., Al Seadi, T. and Oleskowicz-Popiel, P. (2009) The Future of Anaerobic Digestion and Biogas Utilization. Bioresource Technology, 100, 5478-5484. https://doi.org/10.1016/j.biortech.2008.12.046

[51] Chen, Y., Cheng, J.J. and Creamer, K.S. (2008) Inhibition of Anaerobic Digestion Process: A Review. Bioresource Technology, 99, 4044-4064.

[52] Peter-John, M. (1976) Methane: Planning a Digester. Schocken Books, New York, 3.

[53] Reynaud, N. and Buckley, C. (2016) The Anaerobic Baffled Reactor (ABR) Treating Communal Wastewater under Mesophilic Conditions: A Review. Water Science and Technology, 73, 463-478. https://doi.org/10.2166/wst.2015.539

[54] European Commission (2009) Directive 2009/28/EC of the European Parliament and of the Council.

[55] House of Parliament (2011) Anaerobic Digestion.

[56] DEFRA (2011) Anaerobic Digestion Strategy and Action Plan. Gov.uk, London, PB13541.

[57] European Commission (2010) Being Wise with Waste: The EU's Approach to Waste Management.

[58] Green Investment Bank (2015) The UK Anaerobic Digestion Market. GB, London.

[59] Eurostat (2015) Each Person in the EU Generated $481 \mathrm{~kg}$ of Municipal Waste in 2013.

[60] Eurostat (2016) EU Population up to Slightly over 510 Million at 1 January 2016.

[61] DEFRA (2015) 2010 to 2015 Government Policy: Waste and Recycling. Gov.uk, London.

[62] Office of National Statistics (2018) Population of the United Kingdom.

[63] Greater Manchester (2018).

https://www.greatermanchester-ca.gov.uk/site/index.php

[64] DEFRA (2013) Waste and Recycling Statistics. 


\section{List of Acronyms}

$\mathrm{AD}$ : Anaerobic digestion

BMW: Biodegradable municipal

DEFRA: Department for Environment Food \& Rural Affairs

EU: European Union

GDP: Gross domestic product

GM: Greater Manchester

GMWDA: Greater Manchester Waste Disposal Authority

MBT: Mechanical Biological Treatment

MRF: Material Recovery Facility

MSW: Municipal Solid Waste

MW: Megawatt

MWe: Megawatt electric

MWh: Megawatt hour

PFI: Private Finance Initiative

UK: United Kingdom

WDAs: Waste Disposal Authorities

WWDA: Wigan Waste Disposal Authority

WWTP: Waste Water Treatment Plant 